\title{
Extreme capillary heterogeneities and in situ fluid compartmentalization due to clusters of deformation bands in sandstones
}

\author{
Carla R. Romano ${ }^{\mathrm{a}, \mathrm{b}, * 1}$, Charlotte Garing ${ }^{\mathrm{c}}$, James M. Minto ${ }^{\mathrm{a}}$, Sally M. Benson ${ }^{\mathrm{d}}$, Zoe \\ K. Shipton ${ }^{\text {a }}$, Rebecca J. Lunn ${ }^{\mathrm{a}}$

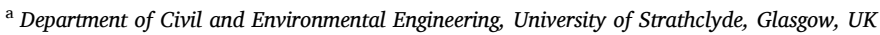 \\ ${ }^{\mathrm{b}}$ Department of Geoscience, University of Wisconsin-Madison, Madison, WI, USA \\ ${ }^{\mathrm{c}}$ Department of Geology, University of Georgia, Athens, USA \\ ${ }^{\mathrm{d}}$ Department of Energy Resources Engineering, School of Earth Sciences, Stanford University, Stanford, USA
}

\section{A R T I C L E I N F O}

\section{Keywords:}

Deformation bands

Multiphase flow

Reservoir compartmentalization

Capillary heterogeneity

X-ray computed tomography

\begin{abstract}
A B S T R A C T
Previous work has shown that individual deformation bands act like capillary barriers and influence fluid saturation. More common in nature, however, are clusters of deformation bands that form complex three dimensional geometries. The aim of this study is to analyze the extent and mechanisms of fluid compartmentalization due to clustered bands. Drainage multiphase fluid flow experiments were performed on a Navajo sandstone core sample characterized by diversely oriented clusters of deformation bands, that sub-divide the host rock into several compartments. Medical X-ray CT images were acquired while nitrogen was injected at progressively higher flow rates into a water-saturated core during transient and steady-state conditions. Spatial and temporal analyses of the non-wetting phase plume migration suggest that deformation bands act like capillary barriers and contribute to the development of an extremely tortuous saturation front. Differential pressure behavior across the core is linked to the breakthrough of $\mathrm{N}_{2}$ into the individual compartments, resulting in highly variable $\mathrm{N}_{2}$ saturation throughout the experiment. Migration into downstream compartments occurs via the exceedance of capillary entry pressure in portions of the bands. Simulation models of simplified systems demonstrate that capillary end effects and discontinuities in the deformation bands impact fluid saturation. The experiments and models presented here show that clusters of deformation bands have the potential to strongly compartmentalize a sandstone reservoir. Hence, prior analysis of the geometry of deformation band structures in a reservoir could significantly reduce the risk of overestimating reservoir capacity, and improve predictions of fluid mobility.
\end{abstract}

\section{Introduction}

Accurate site characterization and understanding of the impact of geology on fluid flow in the subsurface is essential for reservoir management of $\mathrm{CO}_{2}$ geologic storage projects (Chadwick et al., 2004; Cowton et al., 2018; Edlmann et al., 2016; Eiken et al., 2011; Hansen et al., 2013) and enhanced oil recovery operations (Ader and Stein, 1984; Malik and Islam, 2000; Mezzomo et al., 2001; Sheng, 2013). Small-scale heterogeneities, on the scale of millimeters to centimeters, have been demonstrated to have a strong impact on fluid flow at the reservoir scale (Gershenzon et al., 2014; Krevor et al., 2015; Li and Benson, 2015; Lunn et al., 2008; Qu et al., 2017; Rotevatn and Fossen,
2011; Saadatpoor et al., 2010).

Depositional environments and regimes, diagenesis, and structural evolution are all factors promoting multiscale spatial variability of petrophysical and multiphase flow properties in geological reservoirs (Chandler et al., 1989; Morad et al., 2010; Wang et al., 2017; Williams et al., 2017). Variations in the resulting porosity, permeability, capillary pressure, and relative permeability distributions strongly control reservoir quality, injectivity, and fluid/gas capacity. Detailed spatial characterization and quantification of flow properties are required as input parameters for geologic models, necessary for accurate forecasting of important engineering and environmental processes.

Traditional fluid flow property estimation is performed through field

\footnotetext{
* Corresponding author.

E-mail address: cromano3@wisc.edu (C.R. Romano).

1 Current address: Weeks Hall for Geological Sciences, 1215 W. Dayton St., Madison (WI), 53706, USA.
} 
observation, core and core-plug analysis, scaling relationships, and interpretation of borehole log-derived properties (Brown, 1951; Cardwell and Parsons, 1945; Jenning, 1987; Medina et al., 2011; Odling et al., 1999; Willis and White, 2000). Advances in experimental and imaging techniques now enable quantification of fluid flow behavior at the sub-core scale under in situ reservoir conditions. Core flooding experiments, combined with imaging techniques such as X-ray computed tomography (CT), enable measurements of three-dimensional (3D) porosity, permeability, relative permeability, and capillary pressure distribution (Akbarabadi and Piri, 2013; Krause et al., 2013; Krevor et al., 2012; Perrin and Benson, 2010; Pini et al., 2012; Pini and Benson, 2013).

In situ characterization studies of sub-core scale multiphase fluid properties in heterogeneous rocks to date have typically focused on simple structures, such as fractures, bedding planes, laminae (Alemu et al., 2013; Hingerl et al., 2016; Krevor et al., 2011; Li et al., 2020; Ni et al., 2019; Shi et al., 2011) and individual deformation bands (Romano et al., 2020). However, a combination of geologic structures is often present in the subsurface, leading to more extreme heterogeneities with complex geometries. For example, cataclastic deformation bands are often found in conjugate sets and clusters of bands (Antonellini and Aydin, 1994, 1995; Fossen and Hesthammer, 1997; Rawling et al., 2001; Shipton and Cowie, 2001, 2003; Shipton et al., 2005; Sosio de Rosa et al., 2018). Cataclastic deformation bands are millimeter-thick tabular structures occurring in sandstones with porosity higher than 0.15 (Antonellini and Aydin, 1995; Aydin, 1978; Fossen et al., 2007; Saillet and Wibberley, 2010; Schultz and Siddharthan, 2005). They accommodate slip during fault initiation and propagation, and damage zone development (Aydin, 1978; Caine et al., 1996; Shipton and Cowie, 2003). While deformation bands are very commonly reported in aeolian sandstones, they can be also found in laminated, immature sandstones formed in proximal turbiditic deposits or deltaic environments (Antonellini and Mollema, 2002; Del Sole and Antonellini, 2019; Del Sole et al., 2020).

The petrophysical properties of cataclastic bands relate to their mechanism of formation: shearing, along with compaction, leads to grain rolling and fracturing. Deformation band geometry, thickness and properties depend on sorting, grain shape, degree of cementation and mineralogical content of the host rock (Ballas et al., 2015; Fossen et al., 2007, 2018). In all cataclastic bands, fine crushed grains fill available pore spaces, decreasing porosity and permeability of the host rock by several orders of magnitude (Aydin and Johnson, 1978; Antonellini and Aydin, 1994; Ballas et al., 2015; Deng et al., 2015; Fossen et al., 2007; Taylor and Polland, 2000). Cataclastic deformation bands are usually characterized by higher capillary entry pressure values when compared to the surrounding rock (Romano et al., 2020; Torabi et al., 2013; data from Fisher et al., 2005, summarised in van Ojik et al., 2020;). A single deformation band is only able to accommodate few millimeters, or rarely a few centimeters of displacement (Aydin and Johnson, 1978). To accommodate higher displacement, new deformation bands must nucleate, adjacent to the pre-existing bands, resulting in the creation of anastomosing clusters (Aydin and Johnson, 1978; Schultz and Balasko, 2003; Shipton et al., 2002, 2005).

Deformation band frequency tends to decrease with increasing distance from the fault (Schueller et al., 2013; Shipton, et al., 2002). Thick clusters of bands, resulting in very low permeability zones, are likely to be found close to the fault, and within the fault core. The frequency of deformation bands at a given distance from the fault, however, is not related to the maximum fault displacement (Schueller et al., 2013). Clusters of deformation bands characterize the damage zones of small displacement $(<10 \mathrm{~m})$, seismically unresolvable (sub-seismic) faults, hence predicting the presence of deformation bands in a potential reservoir is challenging.

While several studies have highlighted the fact that deformation bands negatively affect fluid flow (Naruk et al., 2009; Qu et al., 2017; Romano et al., 2020; Rotevatn and Fossen, 2011; Rotevatn et al., 2017;
Shipton, et al., 2005; Wilkins et al., 2019), the extent of reservoir compartmentalization induced by deformation bands is unclear. Reservoir compartmentalization happens when fluids are segregated into several saturation/pressure regions due to the presence of barriers. Following the reservoir seals classification proposed by Jolley et al. (2010), due to their petrophysical and multiphase flow properties, deformation bands can be considered as "dynamic barriers", i.e. flow is allowed through the deformation band but the crossflow between host rock compartments is highly reduced, as shown in Romano et al., 2020 in both single and multiphase flow conditions.

There are numerous examples of the impact of geologic structures on fluid compartmentalization in the subsurface (Gainski et al., 2010; Gill et al., 2010; Hansen et al., 2013; Milkov et al., 2007; Richards et al., 2010; Scott et al., 2010; Van Hulten, 2010; Rotevatn et al., 2017). Deformation bands have impacted production in several hydrocarbon reservoirs (for example, Antonellini et al., 1999; Leveille et al., 1997; Lewis and Couples, 1993; van Ojik et al., 2020). One of the clearest examples is reported in a recent study of Wilkins et al., 2019. Results from well pressure tests during- and post-production provided evidence for reservoir compartmentalization within the Holstein Field, Gulf of Mexico (USA). Well cores showed the presence of dense clusters of deformation bands in one of the main oil reservoirs. Analysis of deformation bands density and permeability supported the conclusion that deformation bands acted as flow baffles, influencing well pressure observations. Unexpected reservoir compartmentalization strongly affects injectivity and adds additional uncertainties on potential storage volume and fluid mobility (Smith, 2008). Overly simplified geologic models in reservoir simulations fail to predict fluid compartmentalization. Detailed characterization of the pattern and properties of sub-seismic structures, such as deformation bands, is a key challenge in the avoidance of erroneous reservoir simulation forecasts.

In this study, in situ multiphase fluid behavior in a sandstone characterized by clusters of deformation bands is visualized and quantified. High-resolution X-ray micro-CT images are used to define the geometry of the deformation bands. Conjugate clusters of bands subdivide the host rock into multiple compartments. The core sample in this study is collected from a fault cutting host rock with permeabilities in the 1000 $\mathrm{mD}$ range that could be classified as good quality reservoir if deformation structures are not considered. Drainage core flooding experiments were performed by injecting nitrogen into the water-saturated rock core, while medical X-ray CT images were acquired during both transient and steady-state flow conditions. This in situ imaging at reservoir conditions provides new insights into fluid compartmentalization behavior of deformation bands during multiphase flow.

\section{Materials and methods}

\subsection{Rock sample and $3 D$ porosity}

The rock core chosen for this study was specifically selected to be representative of the complexity that can be found in faults that cut reservoir units. The sample of the Navajo sandstone formation was collected at $60 \mathrm{~m}$ depth in a vertical borehole through the damage zone of a small displacement $(8 \mathrm{~m}$ ) seismically unresolvable normal fault (the Big Hole fault) in Utah (Shipton et al., 2002). The host Navajo Sandstone permeability was characterized in Shipton et al. (2002) based on 2256 probe permeameter measurements on $356 \mathrm{~m}$ of borehole cores drilled through a fault zone, and has permeabilities ranging from $\sim 100 \mathrm{mD}$ to over $4000 \mathrm{mD}$. Host rock permeability declines near the fault core or deformation bands. For this study, the sample was reshaped to $9.8 \mathrm{~cm}$ in length and $5 \mathrm{~cm}$ in diameter (Fig. 1a). A superficial fracture formed towards the outlet of the rock core during core reshaping.

3D digital images of the rock core were obtained with a micro-CT scanner (Nikon XT H 225 LC) in the Advanced Materials Research Lab, University of Strathclyde. The high-resolution images enabled a detailed mapping of internal structures and heterogeneities presented by 
a)

Core sample

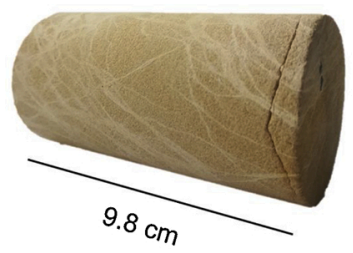

b)

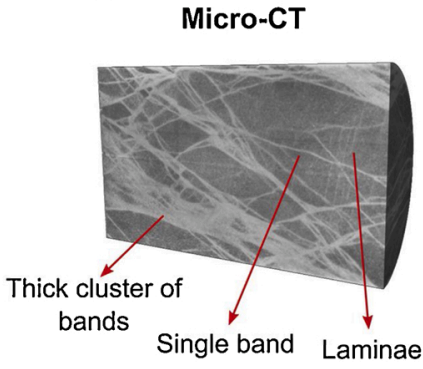

c)

Porosity with medical CT

0

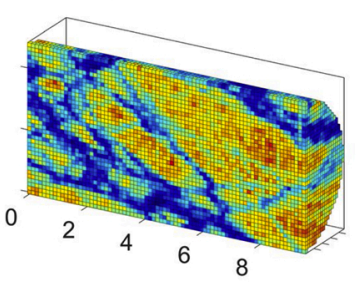

Distance from inlet $(\mathrm{cm})$

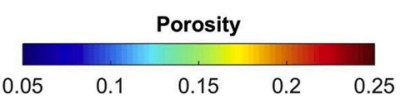

Fig. 1. a) Navajo sandstone core sample characterized by clusters of deformation bands. b) $3 \mathrm{D}$ axial view of the sample obtained with micro-CT images. The core was scanned with the long axis vertically oriented. Several images at the edges of the micro-CT volume were not taken into account because they were affected by cone-beam effect (Cnudde and Boone, 2013). This is an artifact due to the micro-CT cone-beam geometry that affects slices further away from the center of the cone. Voxel size is $0.0275 \times 0.0275 \times 0.0275 \mathrm{~mm}$. Scan time was $\sim 1 \mathrm{~h}$ and $45^{\prime}$. c) 3D Porosity distribution of the rock core obtained using dry and water-saturated medical CT images. Voxel size is $1.25 \times 1.25 \times 1.25 \mathrm{~mm}$. Scan time was $\sim 3^{\prime}$. the rock (Fig. 1b). Deformation bands show higher attenuation values (white) and, therefore are composed of higher density material compared to the host rock. The density in the bands is high due to the mechanism of deformation, which involves grain rolling, fracturing, and subsequent compaction, as opposed to a change in mineralogical composition. The core is characterized by a dense network of deformation bands with angles ranging from $14^{\circ}$ to $31^{\circ}$ relative to the core axis (vertical in the borehole). Deformation bands subdivide the host rock into multiple compartments and decrease in number towards the end of the core (Fig. 1b). It is possible to identify several small-scale structures within the sample: for example, a single deformation band and a thick cluster of bands, that are $0.44 \mathrm{~mm}$ and $11 \mathrm{~mm}$ wide, respectively. Several thin fine-grained laminae perpendicular to the core axis can also be recognized.

A preliminary petrophysical characterization of the rock was obtained by calculating a 3D porosity map of the rock core with a medical X-ray linear scaling technique (Withjack, 1988; Akin and Kovscek, 2003; Mees et al., 2003). Porosity in each voxel $\left(\Phi_{i}\right)$ is calculated as follows

$\Phi_{i}=\frac{C T_{\text {wati }}-C T_{\text {dry }}}{I_{\text {water }}-I_{\text {air }}}$

Here, $C T_{\text {wati }}$ and $C T_{d r y_{i}}$ are CT Hounsfield numbers of water-saturated and dry images, respectively. $I_{\text {water }}$ and $I_{\text {air }}$ are density values, expressed in Hounsfield Units, of water (0 HU) and air (-1000 HU). These images were acquired using a medical X-ray CT scanner (General Electric Hi-Speed CT/i) at Stanford University. A resolution of $0.325 \mathrm{~mm}$ in the $\mathrm{x}-\mathrm{y}$ plane and $0.625 \mathrm{~mm}$ in the $\mathrm{z}$ plane was the highest resolution that could be obtained with the instrument, via acquisition at $120 \mathrm{kV}$ and $200 \mathrm{~mA}$. To reduce noise, three sets of images were acquired, averaged and coarsened, resulting in a voxel dimension of $1.25 \times 1.25 \times 1.25 \mathrm{~mm}$. The lower resolution of the medical CT image prevents the spatial characterization of some structural details that are identifiable in the micro-CT images (Fig. 1b), such as the single band. However, the fast image acquisition offered by the medical CT scanner, compared with the micro-CT scanner, enables imaging during the core flooding experiments. Based on the porosity data in Fig. 1c, the measured bulk porosity for the whole core is 0.138 ; this is comprised of a host rock porosity of approximately 0.2 , and a deformation band porosity of between 0.01 and 0.12 , with an average value for the deformation bands of 0.07 (Fig. 1c).

\subsection{Multiphase core flooding experiments with medical CT scanner}

Steady-state capillary pressure experiments (Pini et al., 2012) were performed on the sample at conditions of $25{ }^{\circ} \mathrm{C}$ and $9 \mathrm{MPa}$, and a confining pressure of 13.4 MPa. A high pressure core flooding experimental setup similar to that reported in other studies is used (Perrin and Benson, 2010; Krevor et al., 2012; Hingerl et al., 2016; Minto et al., 2017; Ni et al., 2019). Details of the setup can be found in Romano et al.,
2020. Due to the mechanical failure of one pump, a single syringe pump was used for nitrogen injection rather than a dual (continuous flow) syringe pump system. The rock core was wrapped with heat-shrinkable Teflon, aluminum foil, more heat-shrinkable Teflon, and a rubber sleeve before being placed in an aluminum core holder connected to the core flooding experimental setup. During the experiments, medical X-ray CT images were acquired with the same settings specified in section 2.1. Pressure at the inlet and outlet of the core was measured by two pressure transducers. Nitrogen was first injected into the core in order to acquire baseline scans of the $\mathrm{N}_{2}$-saturated rock core at the experimental conditions. The core was then flushed with $\mathrm{CO}_{2}$ in order to displace the $\mathrm{N}_{2}$ and prior to saturate the core with water.

Before injecting the non-wetting fluid $\left(\mathrm{N}_{2}\right)$ into the water-saturated core, single phase water injection was performed for measuring bulk permeability. Water was injected at several flow rates in the watersaturated sample and the corresponding pressure drop values across the core were recorded. By applying Darcy's law, a bulk intrinsic permeability of $0.18 \mathrm{mD}$ of the entire sample was calculated.

The fluid pair used in the multiphase experiment was $\mathrm{N}_{2}$ and water. Nitrogen was chosen as the non-wetting phase instead of $\mathrm{CO}_{2}$ for its lower solubility in water and thus to reduce experiment complications related to gas dissolution. Past experimental studies have shown that $\mathrm{N}_{2}$ is an excellent analogue for $\mathrm{CO}_{2}$. Although contact angle and surface tension values are different in $\mathrm{N}_{2}$ /water and $\mathrm{CO}_{2}$ /water systems, it has been shown that in both conditions the rocks are strongly water-wet and the difference in wetting states can be corrected for, in multiphase flow analysis (Al-Menhali et al., 2015; Garing and Benson, 2019; Niu et al., 2015; Pini and Benson, 2013; Plug and Bruining, 2007).

The water was pre-equilibrated with nitrogen for several hours for preventing $\mathrm{N}_{2}$ dissolution during injection. Multiphase core flooding experiments consisted of injecting $100 \% \mathrm{~N}_{2}$ at progressively higher flow rates $(0.3,0.6,0.8,1,2 \mathrm{~mL} / \mathrm{min})$ into the initially water-saturated sample. Five pore volumes (PV) of injected fluid are generally considered enough to reach steady-state pressure and saturation conditions (Perrin et al., 2009). However, in this highly heterogeneous rock sample, more than 10 pore volumes $(1 \mathrm{PV}=26.7 \mathrm{~mL}$ ) were needed.

Nitrogen saturation within individual voxels $\left(S_{N_{2 i}}\right)$ can be estimated using Eq. 2 by acquiring several sets of medical X-ray CT images (Akin and Kovscek, 2003).

$S_{N_{2 i}}=\frac{C T_{\exp _{i}}-C T_{\text {wat sat } i}}{C T_{N 2 \text { sati }}-C T_{\text {wat sat } i}}$

Here $C T_{\exp _{i}}, C T_{\text {wat sati }}, C T_{N 2 \text { sati }}$ are scan images at experimental, fully water-saturated and fully $\mathrm{N}_{2}$-saturated conditions, respectively. Once steady-state conditions were reached for each injection flow rate, at least three sets of images were acquired and averaged to reduce the random error in the CT measurements (Pini et al., 2012). Images were coarsened, up to a resolution of $1.25 \mathrm{~mm}$ in the $\mathrm{x}-\mathrm{y}-\mathrm{z}$ plane, for further noise reduction, as for the voxel porosity calculation (section 2.1). Medical CT 
images were also taken during experimental transient conditions in order to quantify the dynamic behavior of $\mathrm{N}_{2}$ invasion into different compartments of the core. During transient conditions, only single CT scans were acquired.

\section{Experimental results: sealing effect of deformation bands on fluid flow}

\subsection{Sub-core scale $N_{2}$ saturation in transient and steady-state conditions}

The first stage of injection was performed by injecting $\mathrm{N}_{2}$ at $0.3 \mathrm{~mL} /$ $\mathrm{min}$. After $50 \mathrm{~min}$ of injection at $0.3 \mathrm{~mL} / \mathrm{min}(0.55 \mathrm{PV})$, some of the compartments near the inlet reach a high $\mathrm{N}_{2}$ saturation (Fig. 2a). Migration of the $\mathrm{N}_{2}$ is characterized by tortuous connections, rather than the relatively uniform saturation front observed in more homogenous systems. Looking more closely at the two dimensional (2D) cross section, or slice, in the $x-y$ plane, at $1 \mathrm{~cm}$ from the inlet, it is noticeable that there remain areas with near zero $\mathrm{N}_{2}$ saturation (Fig. $2 \mathrm{~b}$, marked with an arrow). Due to the low resolution of the medical CT images, it is not easy to relate this effect to a specific rock feature. However, the highresolution dry micro-CT image of the corresponding slice (Fig. 2e) provides the structural details necessary to link the zero $\mathrm{N}_{2}$ saturation area to a thick cluster of anastomosing bands that prevent this region and any enclosed compartments, from becoming saturated.

Slices at 4.12 and $4.6 \mathrm{~cm}$ from the inlet provide more evidence of the high degree of tortuosity and complexity of 3D compartments' geometry and connectivity. Higher $\mathrm{N}_{2}$ saturation is measured in the central compartment of the slice at $4.6 \mathrm{~cm}$ from inlet, compared to the one at $4.12 \mathrm{~cm}$ (Fig. 2c, 2d). This is because the portion of the rock further away from the inlet is saturated through a flow pathway that originates from the left side, whereas in the slice closer to the inlet, invasion is slower and occurs from the right side. The central compartment of these two slices (Fig. 2c, 2d) is subdivided by a thin deformation band that acts as a capillary barrier, delaying crossflow between the two sub-regions (Fig. $2 \mathrm{~g}, 2 \mathrm{~h}$ ).

At $5.3 \mathrm{~cm}$ from inlet, only a few compartments are saturated with $\mathrm{N}_{2}$ (Fig. 2e). The areas that maintain high water saturation correspond to host rock regions isolated from the inlet, by thick clusters of bands

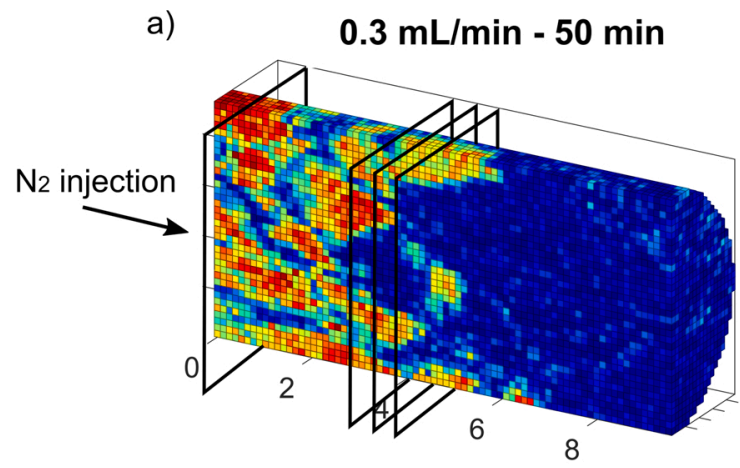

Distance from inlet $(\mathrm{cm})$

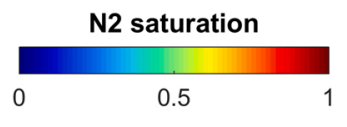

c)

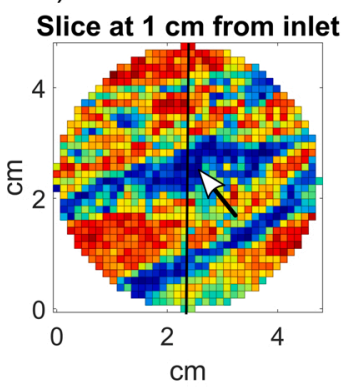

Slice at $4.12 \mathrm{~cm}$ from inlet

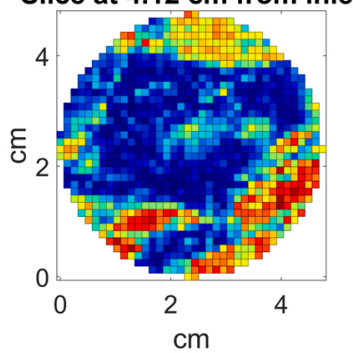

Micro-CT

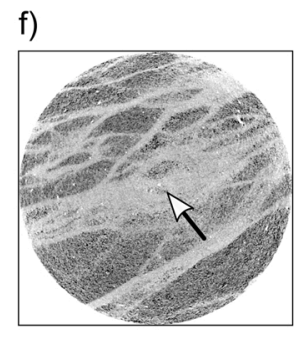

h)

g)

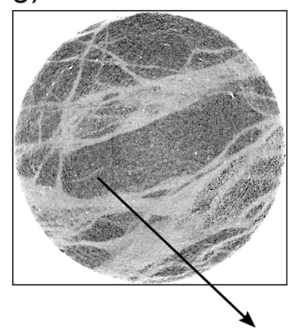

d)

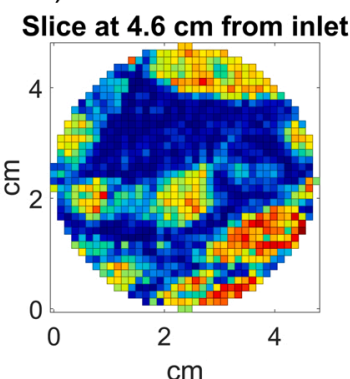

e)

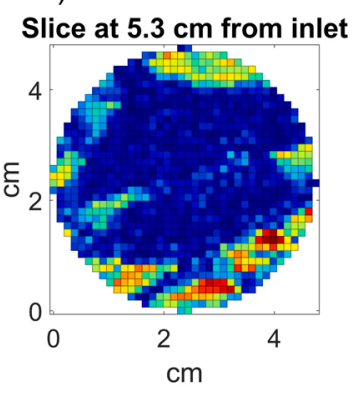

i)

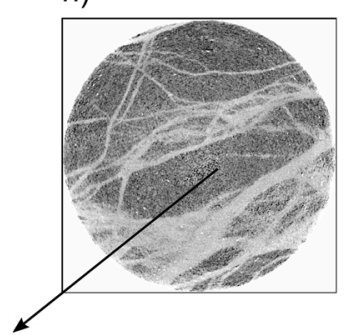

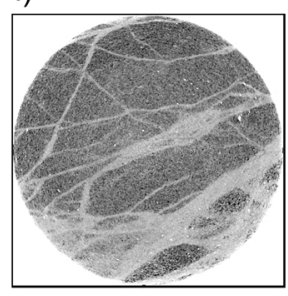

Thin deformation band

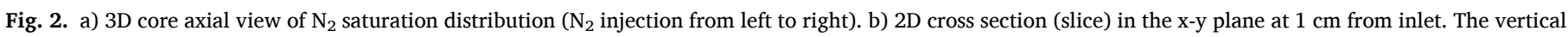

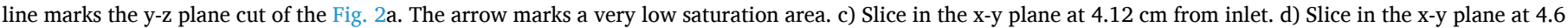

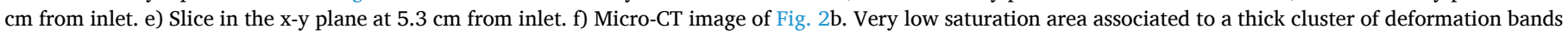

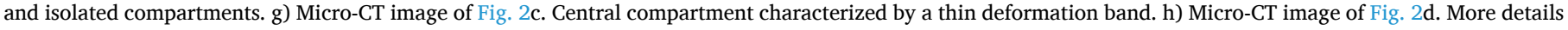
of the central compartment and the thin deformation band. i) Micro-CT image of Fig. 2e. 
(Fig. 2i).

Still with an injection rate of $\mathrm{N}_{2}$ at $0.3 \mathrm{~mL} / \mathrm{min}$, as time increases, nitrogen progressively saturates new compartments that were previously water-saturated (Fig. 3a). After $3 \mathrm{~h}$ (corresponding to $2 \mathrm{PV}$ ), $\mathrm{N}_{2}$ has saturated some compartments near the end of the core. Fig. $3 \mathrm{~b}$ shows the temporal evolution of $\mathrm{N}_{2}$ saturation for a slice at $5.3 \mathrm{~cm}$ from inlet. The $\mathrm{x}-\mathrm{y}$ plane is characterized by several compartments, three of which are marked with a circle, a rhombus, and a square. The first and second of these are separated by a thick anastomosing cluster of bands. The second and third compartments, however, are only subdivided by a single deformation band (Fig. 2i). Despite this, the most prominent barrier between compartments is the single deformation band, shown in Fig. 1b, which has a near-parallel orientation to the flow direction.

At $50 \mathrm{~min}$ from injection, only the compartment marked with a circle is partially saturated with $\mathrm{N}_{2}$. In this compartment, very high $\mathrm{N}_{2}$ saturation is reached after continuously injecting for $80 \mathrm{~min}(1 \mathrm{PV})$. This is strong evidence of the sealing capacity of the deformation bands. At $3 \mathrm{~h}$ of injection, $\mathrm{N}_{2}$ invades the region marked with a rhombus. At this time, portions of the deformation band, that until previously had shown zero $\mathrm{N}_{2}$ saturation, start to become saturated. This can be explained by the fact that a single band is characterized by several pore throat sizes and entry pressure values. It is likely that some portions of the deformation band with lower entry pressure are saturated earlier, creating new pathways between different compartments. Steady-state conditions are reached after more than $15 \mathrm{~h}$ of injection. At this time the compartment marked with a square still remains water-saturated.

Fig. 4 shows the $\mathrm{N}_{2}$ saturation distribution at steady-state conditions for all (progressively increasing) flow rates. The main change to saturation is seen in the compartment marked with a square in Fig. 3. The migration of $\mathrm{N}_{2}$ in this compartment is strongly affected by the finegrained laminae shown in Fig. 1b. Very high $\mathrm{N}_{2}$ saturation characterizes the first half of the rock core even at low flow rates. The thick diagonal cluster that traverses the sample from $3 \mathrm{~cm}$ to $8 \mathrm{~cm}$ from the inlet, acts as the main capillary barrier in the core. This is illustrated by the upstream accumulation of $\mathrm{N}_{2}$ behind this cluster. At the highest flow rate of $2 \mathrm{~mL} /$ min, with a high differential pressure across the core of $1.8 \mathrm{MPa}$, two compartments near the outlet still have almost zero $\mathrm{N}_{2}$ saturation. In the top compartment, this behavior is due to the presence of a thick cluster of deformation bands. At the end of the experiment, a few other small compartments exhibit very low $\mathrm{N}_{2}$ saturation. In the micro-CT image these regions, marked with black circles in Fig. 4, are enclosed by multiple bands, with the result that $\mathrm{N}_{2}$ simply bypasses them. Deformation bands themselves are characterized by low $\mathrm{N}_{2}$ saturation, with some portions having almost zero $\mathrm{N}_{2}$ saturation. This is further evidence that pathways are localized onto "weak points" or discontinuities in the bands with lower capillary entry pressure, and that these small breaches are enough to connect compartments and maintain steady stateconditions.

\subsection{Evolution of nitrogen migration in single compartments}

To understand the temporal evolution in $\mathrm{N}_{2}$ saturation between compartments, the core was divided into discrete volumes of host rock compartmentalized by deformation bands. Image processing of dry medical X-ray CT scans (which gave the greatest contrast between host rock and deformation band) resulted in 167 such compartments. For a)

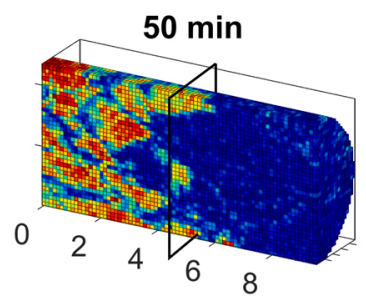

Distance from inlet $(\mathrm{cm})$

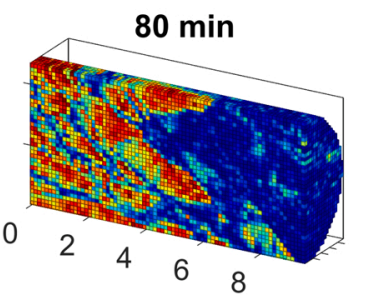

Distance from inlet $(\mathrm{cm})$

\section{$0.3 \mathrm{~mL} / \mathrm{min}$}

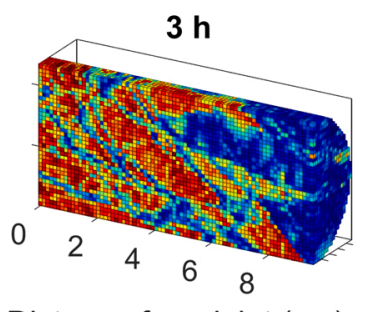

Distance from inlet $(\mathrm{cm})$

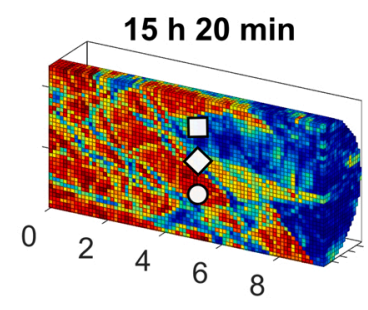

Distance from inlet $(\mathrm{cm})$ b)

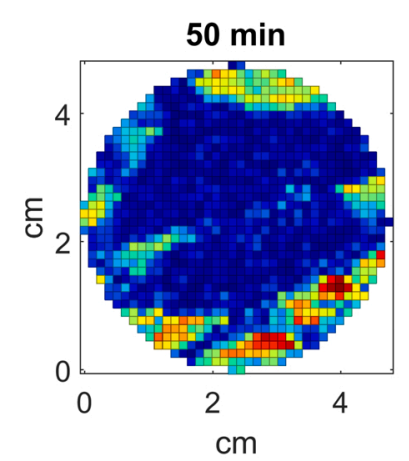

\section{Slice at $5.3 \mathrm{~cm}$ from inlet}

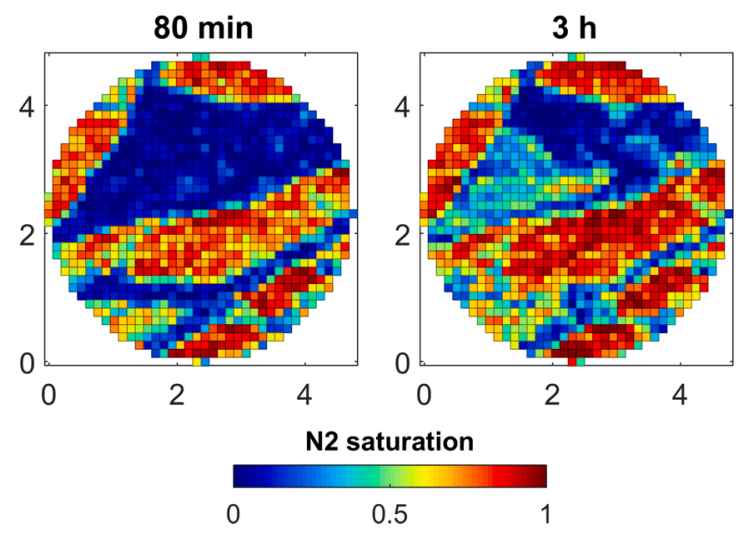

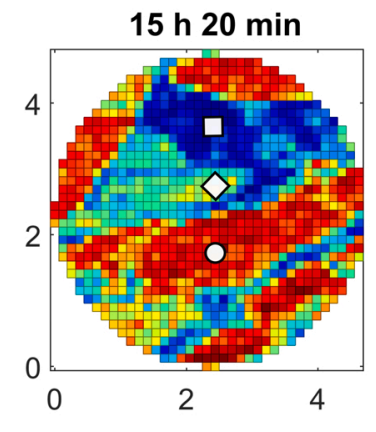

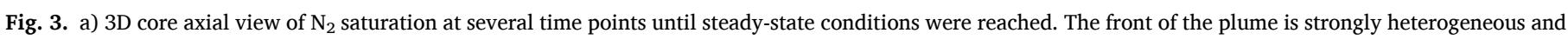

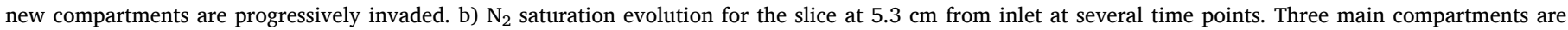

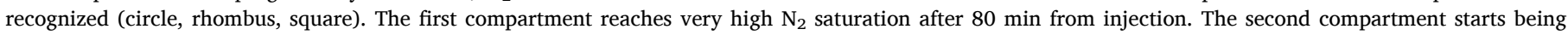

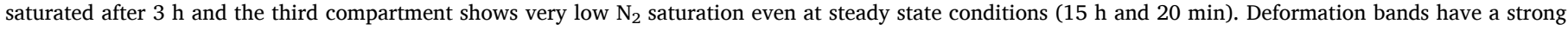
sealing effect. Portions of bands are progressively saturated, allowing fluid migration across compartments. 
$0.3 \mathrm{~mL} / \mathrm{min}$

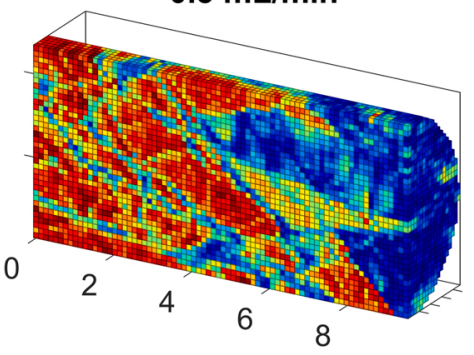

Distance from inlet $(\mathrm{cm})$

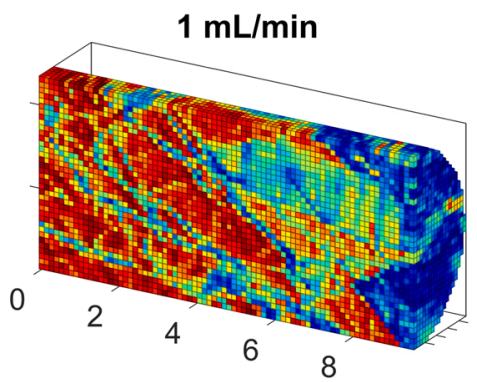

Distance from inlet $(\mathrm{cm})$

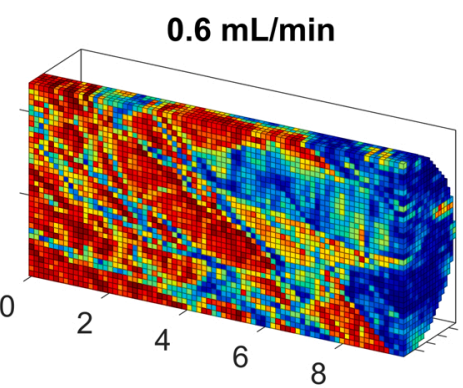

Distance from inlet $(\mathrm{cm})$

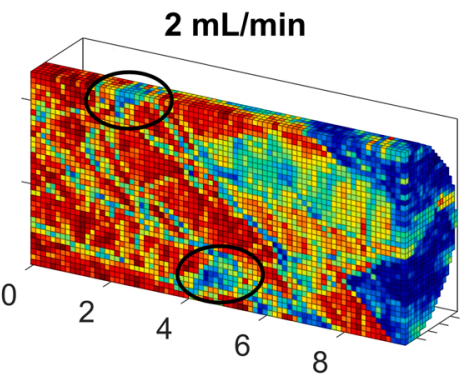

Distance from inlet $(\mathrm{cm})$

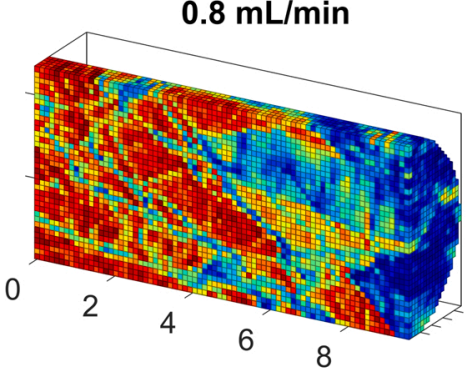

Distance from inlet $(\mathrm{cm})$

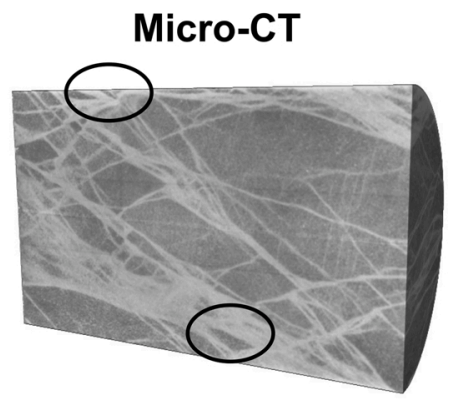

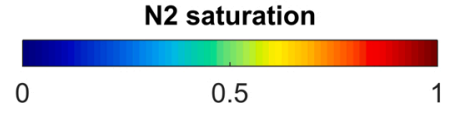

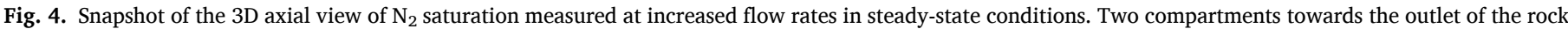

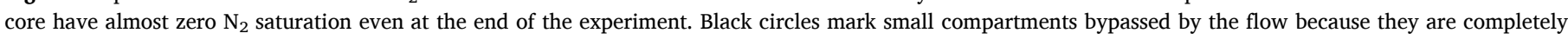
isolated by multiple bands as shown in the micro-CT image.

simplicity, only the largest regions are considered, resulting in 12 compartments, each consisting of more than 4000 voxels. Considering that portions of the rock near the inlet reached a very high $\mathrm{N}_{2}$ saturation immediately on commencing injection, only the compartments placed beyond $2 \mathrm{~cm}$ from inlet were considered; this resulted in 7 compartments, which are shown in Fig. 5a. In each of them, the average $\mathrm{N}_{2}$ saturation was calculated over time, using single sets of medical CT images (without averaging between scans); in total, 97 scans were analyzed.

The compartments, $c_{i}$ ( $i$ from 1 to 7 ), are numbered based on the a)

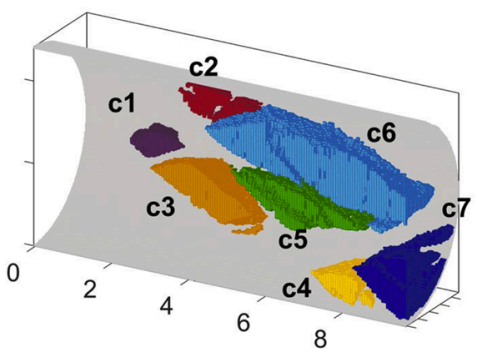

Distance from inlet $(\mathrm{cm})$

c)

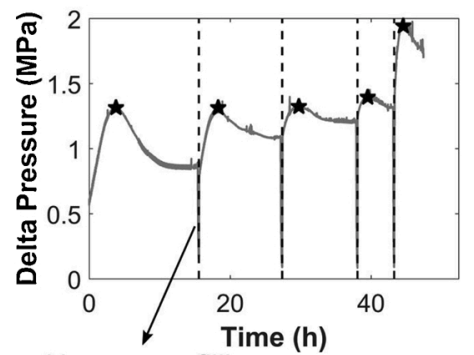

N2 pump refilling b)

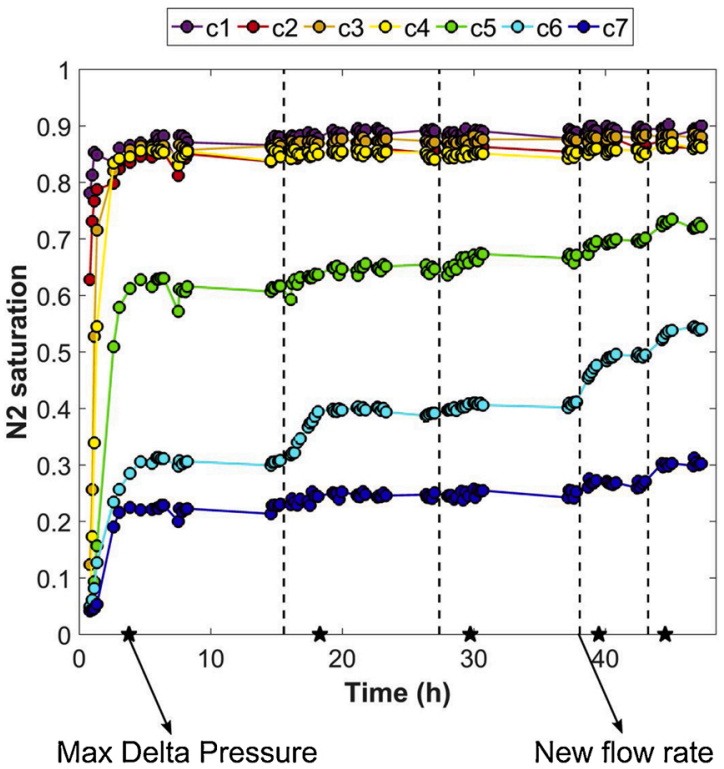

Fig. 5. a) 3D axial view of the seven compartments identified for saturation analysis across the core. They are numerically ordered based on the arrival time of $\mathrm{N}_{2}$. b) Plots of saturation in each compartment for each full-core CT scan (circles). Increase of $\mathrm{N}_{2}$ saturation in compartments 5, 6, and 7 when new flow rates are imposed (dashed vertical lines). Stepped increases in saturation correspond to maxima in pressure differential (stars). c) Delta pressure profile during the experiments. For each flow rate, the same trend is measured: the pressure builds up until a maximum value and then decreases and plateaus. At 1 and $2 \mathrm{~mL} / \mathrm{min}$, due to usage of the full volume of the $\mathrm{N}_{2}$ pump, injection was stopped. Steady-state conditions may not have been reached. The negative spikes at the end of each flow rate are due to the refilling of the $\mathrm{N}_{2}$ pump. 
arrival time of the $\mathrm{N}_{2}$ (Fig. 5a). Compartments 1 (c1), 2, and 3 begin to be invaded by the non-wetting phase, $\mathrm{N}_{2}$, from the very first stages of injection and reach a steady-state saturation within five hours (3.4 PV).

Compartment 4 reaches very high $\mathrm{N}_{2}$ saturation before compartments 5 and 6 , despite being further from the inlet (Fig. 5b). This is evidence of the complexity of the 3D flow path connectivity in the rock.

In compartments 5,6 , and $7, \mathrm{~N}_{2}$ saturation progressively increases when a higher flow rate, and therefore higher injection pressure, is imposed (Fig. 5b). At the end of the experiments, the seven analyzed compartments exhibit very different final $\mathrm{N}_{2}$ saturation values. The stepped increases in saturation in these compartments correspond to temporary peaks in the differential pressure measured across the core (measured with pressure transducers at core inlet and outlet). For each flow rate, the delta pressure follows the same trend: it builds up until a maximum value $(1.31,1.31,1.32,1.4$, and $1.95 \mathrm{MPa})$ and then decreases and plateaus (Fig. 5c). The maximum values reached can be interpreted as pressure threshold values at which $\mathrm{N}_{2}$ is able to breach a capillary barrier and flow through into a lower saturation region.

Overall, a flow rate of $0.3 \mathrm{~mL} / \mathrm{min}$ and a corresponding maximum pressure of $1.31 \mathrm{MPa}$, is enough to exceed the capillary entry pressure of portions of deformation bands enclosing the seven compartments. Compartments 5, 6, and 7 are likely to have low $\mathrm{N}_{2}$ saturation due to the capillary end effect. However, the fact that compartment 4, also placed near the outlet, shows high $\mathrm{N}_{2}$ saturation is indicative of the fact that the capillary end effect is not the only reason why low saturation is experienced in compartments 5, 6 and 7, as explained in section 4.2.

\section{Factors influencing compartments' saturation}

\subsection{Model characterization, initial and boundary conditions}

Multiphase flow simulations were conducted to better understand how the deformation bands influence fluid flow. For this purpose, the Stanford University General Purpose Research Simulator (GPRS) was used (Cao, 2002; Jiang, 2008; Li, 2011; Boon et al., 2018; Cao and Aziz, 2002; Krause, 2012; Krause et al., 2013; Li et al., 2012; Li and Benson, 2015). Considering the 3D complexity of the core, the aim is not to accurately replicate the experimental results, rather to explore the effects on saturation of the experimental boundary conditions (capillary end effect) and to understand how discontinuities in the bands may affect the saturation profiles. As a consequence, simplified 2D models were built for the simulations, each with a grid of $35 \times 78$ cells, equivalent to a resolution in the $\mathrm{y}$ and $\mathrm{z}$ plane of $1.25 \mathrm{~mm}$ (the same dimensions as the medical CT scans). Deformation bands discretize the host rock in 8 compartments. Model sketch, boundary conditions, and injection strategy are included in Figure S1 of the Supplementary material.

Model cells are categorized as either host rock or deformation band with assigned porosity of 0.16 and 0.07 , respectively. Permeability values are estimated using the permeability-porosity relationship proposed by Torabi et al. (2013). With this, a permeability of $89 \mathrm{mD}$ was assigned to the host rock and $0.04 \mathrm{mD}$ to the deformation bands. The capillary pressure curve was calculated by fitting a Brooks-Corey model (Brooks and Corey, 1964) to capillary pressure values measured during the experiments (Figure S2 in Supplementary material). Entry pressure values of $7 \mathrm{kPa}$ and $220 \mathrm{kPa}$ were estimated for the host rock and the deformation bands, respectively. The relative permeability curve, assigned using the Brooks-Corey model, is shown in the Supplementary material (Figure S3). Modeling assumptions, details for the capillary entry pressure, and the method of relative permeability estimation can be found in Romano et al., 2020. The capillary end effect is simulated by placing a small reservoir with high porosity and permeability and very low entry pressure $(0.02 \mathrm{kPa})$ at the end of the model, using the same approach as in Romano et al., 2020.

\subsection{Multiphase flow modeling results}

In the first model simulation (Fig. 6a), saturation increases in the compartment upstream of the first band, which acts as a capillary barrier. The plume has to pass through the band before invading compartments 2, 3, and 4 (see compartment numbers in Figure S1 for reference). After $20 \mathrm{~h}$ of injection at $0.3 \mathrm{~mL} / \mathrm{min}$ (Fig. $6 \mathrm{~b}$ ), $\mathrm{N}_{2}$ saturation reaches very high values in the compartments that are not in contact with the outlet (1-5). Deformation bands become more saturated than previously but still show very low $\mathrm{N}_{2}$ saturation. The three compartments placed at the outlet $(6,7,8)$ are characterized by a decreasing

\section{End effect}

a)

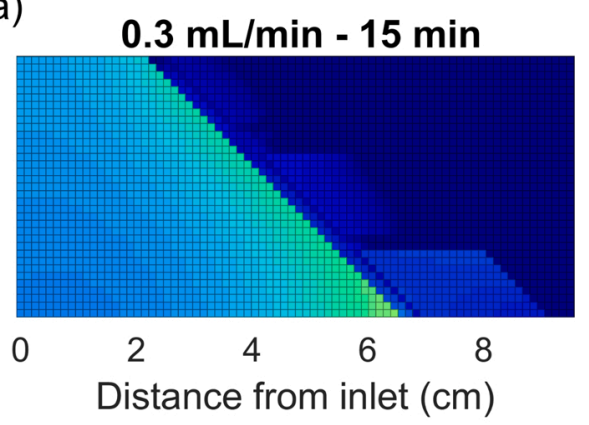

b)

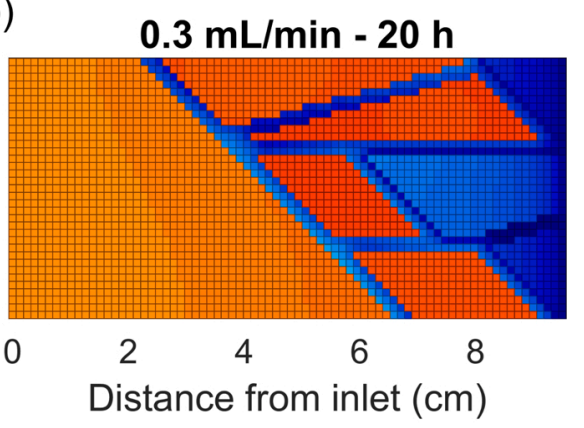

c)
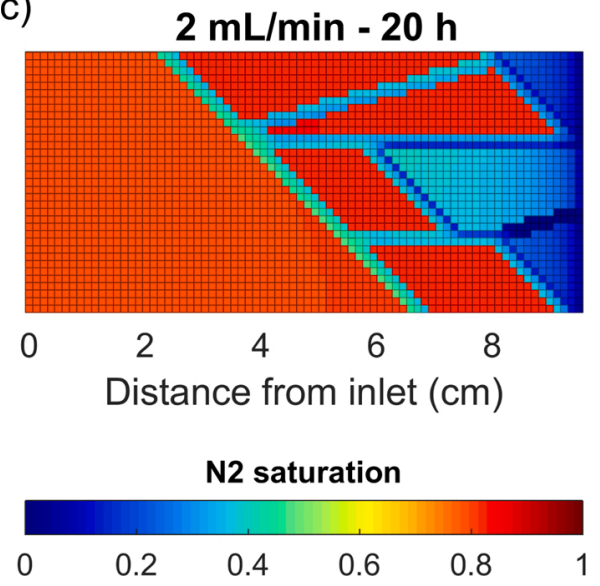

Fig. 6. a) Simulation results of the model with a small reservoir at the end (capillary end effect) after $15 \mathrm{~min}$ at $0.3 \mathrm{~mL} / \mathrm{min}$. The compartment before the band shows nitrogen saturation build up. b) Simulation results after $20 \mathrm{~h}$ of injection at $0.3 \mathrm{~mL} / \mathrm{min}$. Negative trend in the compartments at the outlet due to capillary end effect. c) Results at the end of the simulation ( $20 \mathrm{~h}$ at $2 \mathrm{~mL} / \mathrm{min}$, $100 \mathrm{~h}$ total from first injection). Fluid compartmentalization occurs in areas not affected by the capillary end effect. Bands closer to the outlet emphasize the capillary end effect in compartments 7 and 8 but limit its spatial extension. 
trend in $\mathrm{N}_{2}$ saturation. This is attributed to the presence of the small reservoir at the end of the model (i.e. the capillary end effect). At the end of the simulation (Fig. $6 \mathrm{c}$ ), the decreasing trend due to the capillary end effect dominates the fluid saturation in compartments 6,7 , and 8 . The presence of bands towards the outlet (confining compartments 7 and 8) acts to limit the upstream extension of the capillary end effect. It is notable that compartments $2,3,4$, and 5 have higher saturation than compartment 1 , and that fluid compartmentalization happens, regardless of any capillary end effect. The model clearly captures many of the key processes - compartment invasion, end effects, and a progressive non-homogeneous saturation front - that were observed in the experiment.

In the second model simulation, discontinuities (holes) were introduced into the deformation bands by assigning host rock petrophysical

\section{End effect and discontinuities in bands}

a)

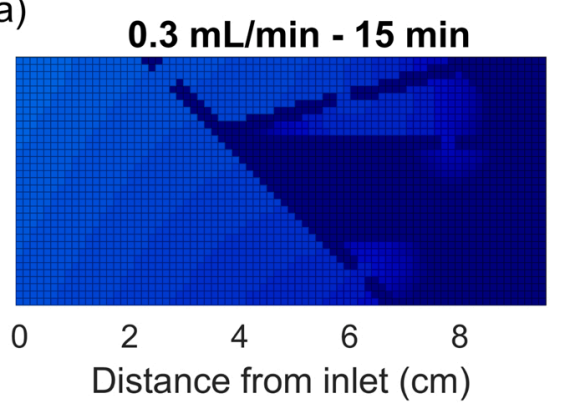

b)

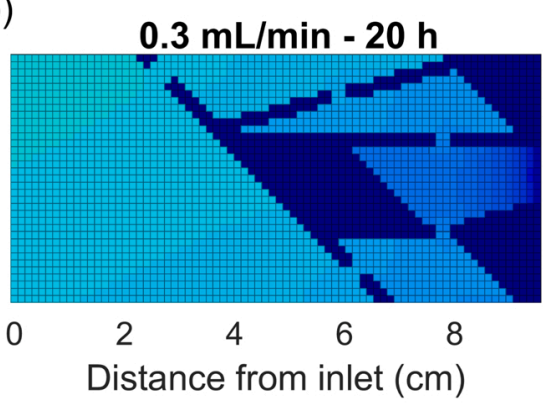

c)
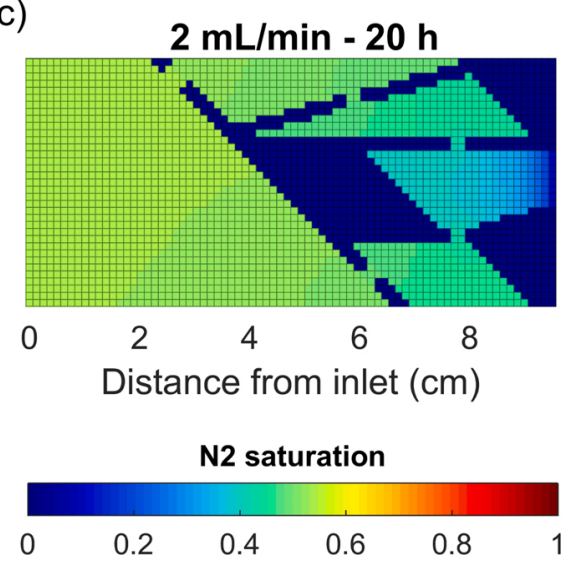

Fig. 7. a) Simulation results of the model with capillary end effect and discontinuities in the bands after $10 \mathrm{~min}$ at $0.3 \mathrm{~mL} / \mathrm{min}$. The order in which compartments are invaded differs from the first model. b) Simulation results after $20 \mathrm{~h}$ of injection at $0.3 \mathrm{~mL} / \mathrm{min}$. Bands, compartments 3,7 , and 8 are bypassed. c) Simulation results at the end of the simulation $(20 \mathrm{~h}$ at $2 \mathrm{~mL} / \mathrm{min}$, $100 \mathrm{~h}$ total from first injection). Bands, compartments 3, 7, and 8 are still bypassed. Lower $\mathrm{N}_{2}$ saturation compared to the first model. properties to a cluster of cells in five short sections of the bands (visible as the five gaps in Fig. 7b). These discontinuities provide pathways for fluids and act to prevent saturation build up in compartment 1 , upstream of the first band. After $20 \mathrm{~h}$ of injection at $0.3 \mathrm{~mL} / \mathrm{min}$ (Fig. $7 \mathrm{~b}$ ), $\mathrm{N}_{2}$ saturation is much lower throughout the core when compared to the previous model simulation (Fig. 6). Compartments 3, 7, and 8 show zero $\mathrm{N}_{2}$ saturation and are completely bypassed by flow because of the presence of the discontinuities. A negative trend in saturation, due to the capillary end effect, can be seen in the central compartment in contact with the outlet (compartment 6). At the end of the simulation (Fig. 7c), $\mathrm{N}_{2}$ saturation has increased in all host rock regions, with the exception of compartments 3,7 , and 8 that are still by-passed by the $\mathrm{N}_{2}$ and have zero $\mathrm{N}_{2}$ saturation. The overall $\mathrm{N}_{2}$ saturation in this model is lower than in the previous one.

These simulation results suggest that discontinuities in the bands can reduce the buildup of pressure and nitrogen saturation in the host rock upstream of the deformation bands. By comparison, a combination of discontinuities in the bands with low entry pressure and the capillary end effect may explain the very low saturation in the bottom compartment at the outlet of the experimental core (Fig. 4).

\section{Impact of deformation band clusters on two-phase flow}

The effect of clusters of deformation bands on two-phase fluid flow has been visualized in situ and analyzed in this study. Clusters of deformation bands strongly increase the structural complexity and 3D anisotropy of high porosity sandstone reservoirs. They subdivide the host rock into multiple compartments that are not easy to geometrically define in 3D. Due to their mechanism of formation, cataclastic bands are characterized by reduced porosity and permeability and a higher capillary entry pressure when compared to the host rock. In the case of deformation band clusters, the sealing effect on flow is more marked compared to either a single cataclastic band or the laminae alone. This is analogous to the results shown in Romano et al., 2020, in which even individual cataclastic deformation bands have a higher effect on permeability during single and non-wetting fluid saturation multiphase flow than fine-grained laminae.

As mentioned in section 2.2, the bulk permeability of the core sample is $0.18 \mathrm{mD}$ and this permeability value is certainly not representative of an undeformed, good quality carbon storage reservoir. However, Shipton et al. (2002) show that the host rock permeability measured in adjacent core samples ranges between $\sim 100 \mathrm{mD}$ to over $4000 \mathrm{mD}$, with an average of $620 \mathrm{mD}$ for unstratified host rock and $170 \mathrm{mD}$ for stratified host rock, which is typical of a good quality reservoir rock. The presence of deformation band clusters has reduced the sample bulk permeability by three orders of magnitude. Dense clusters of deformation bands are sub-seismic features associated with sub-seismic faults, as discussed further in this section.Such conjugate sub-seismic faults are commonly found in nature in high porosity sandstones (see references in the introduction), resulting in spatially localized permeability (or porosity, Fig. 2c) reductions that act to compartmentalize the reservoir in a similar way at larger scales.

It is generally expected that during primary drainage compartments would be invaded in sequence with distance from the injection point, however, our experimental results clearly prove that this is not always true (Fig. 5). As the compartments are invaded, breaching commonly occurs through a small portion of the band. This may be governed by discontinuities in the band network, or by varying petrophysical properties within the band itself, resulting in sections with lower capillary entry pressures, locally. This potentially leaves the remaining portions of the bands unsaturated and can create new tortuous flow paths that bypass entire compartments (as shown in Fig. 7). The integrity and thickness of the bands clearly matter to how well-compartmentalized different regions of the host rock are. It may not be sufficient to assign a single set of petrophysical properties to the entire band for simulating their effect on fluid flow, as is commonly the case in reservoir 
simulations. Instead, a stochastic approach may be more appropriate.

Several studies have discussed that reservoir compartmentalization due to the presence of deformation bands may never happen. Tindall (2006) highlighted that deformation bands act as "stiff mechanical layers", that develop joints with spacing linearly related to the mean thickness of deformation bands. The joints represent potential fluid pathways, connecting high porosity and permeability regions and bypassing the low porosity and permeability deformation band zone. In this study, a thick cluster of bands (cb2) crosscuts another cluster of bands (cb1), without developing any joints or fractures (Fig. 8). Indeed, no joints or fractures are present in the core at all. Hence, for predictive studies, it will be important to determine the geological conditions that are likely to promote such cross-cutting joints and the frequency of their occurrence.

Medeiros et al. (2010) suggest that deformation bands have a limited role in compartmentalization due to their vertical and horizontal limited extension. Whilst this may be true for each single deformation band zone, it is common to find in nature more complex systems characterized by overlapping faults (Childs et al., 2009; Johansen and Fossen, 2008; Shipton and Cowie, 2001). Large displacement faults can develop adjacent synthetic and antithetic small faults (Berg and Skar, 2005; Bonson et al., 2007; Kim et al., 2004; Torabi, 2014) and in small faults synthetic and antithetic clusters of deformation bands can be found (Johansen and Fossen, 2008; Pontes et al., 2019; Shipton and Cowie, 2001, 2003; Shipton et al., 2005). An example is shown in Fig. 9a; the photograph is taken from the same field site as the rock core in this study (Shipton et al., 2002). The main fault and the surrounding deformation band-dominated damage zone have sub-seismic resolution and the clusters of bands are conjugate. Synthetic and antithetic clusters are

\section{Micro-CT}
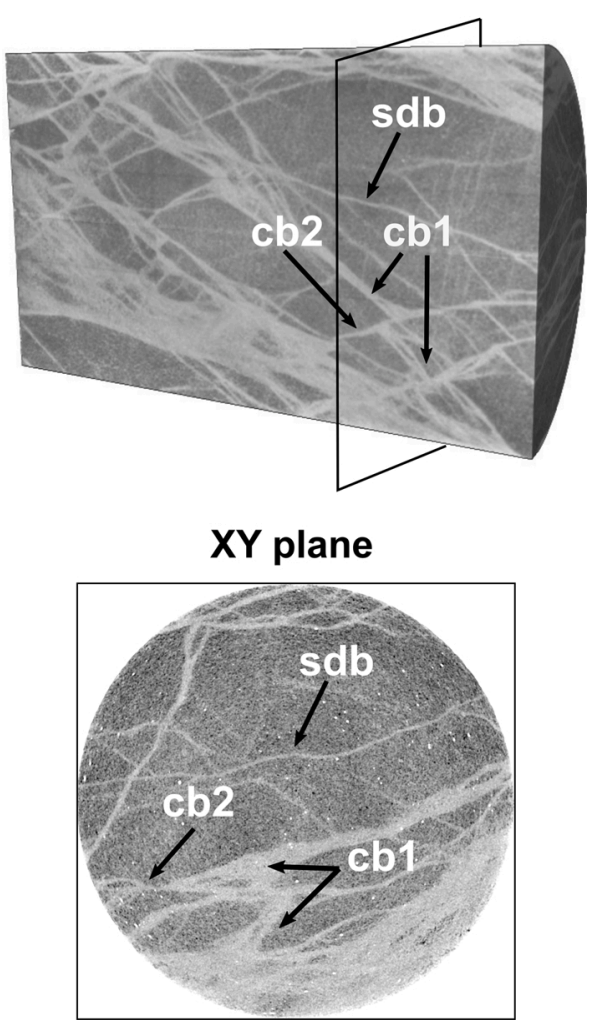

Fig. 8. (top) Axial view of micro-CT images of the rock core. (bottom) Slice corresponding to the $\mathrm{x}-\mathrm{y}$ plane drawn in the top figure. The diagonal cluster of bands marked with cb1 is crosscut by a second cluster $\mathrm{cb} 2$. In the $\mathrm{x}$-y plane slice is better shown the offset and the difference between clusters and single deformation bands (sdb). apparent at the outcrop (m-cm scale) scale (Fig. 9b, 9c) and at the core scale (mm scale) as shown in the core sample used in this study. In addition, in certain circumstances, individual layers can become saturated with deformation bands (Fossen and Hesthammer, 1997; Griffiths et al., 2018; Saillet and Wibberley, 2010).

Predicting fluid mobility is hard to achieve due to the sub-seismic nature of deformation bands, and their variable geometry, thickness, and orientation. Injection in a reservoir characterized by clusters of deformation bands would likely lead to fluid compartmentalization and fluid channeling in lozenge-shaped compartments. In the best-case scenario, where later fractures create connectivity between higher permeability areas, overestimation of potential reservoir capacity will still occur. Additional complications may occur when injecting fluids into deformation bands zones formed in a strike-slip regime. In this case, the lozenge-shaped compartments would likely have a long axis perpendicular to bedding, leading to orthorhombic regions limited in their extent by bed thickness.

Unexpected compartmentalization due to clusters of deformation bands could also occur in highly permeable reservoirs when the plume is migrating across a fault zone where sand lithologies are juxtaposed. Indeed there are cases where cross fault pressure differences have been observed at sand-sand juxtapositions that were expected to leak, where deformation bands could be responsible for a cross-seal fault behavior, as documented by Smith (1980).

Our experiments show that deformation bands negatively affect drainage processes. However, once a compartment has been invaded, they could act to enhance capillary trapping. As shown in several studies on the effects of bedding and laminations in sediments, such capillary heterogeneities influence residual trapping during secondary imbibition. Specifically, it has been shown that significant amounts of $\mathrm{CO}_{2}$ can be residually trapped upstream of local capillary barriers (Krevor et al., 2011; Jackson and Krevor, 2019; Meckel et al., 2015). If this is true for conjugate deformation bands, then even though in hydrocarbon and carbon storage reservoirs deformation bands are considered to reduce the quality of the reservoir by inhibiting flow, for CCS, they may increase trapping efficiency when compared to homogeneous sandstones. Predicting the initial-residual saturation (IR) relationship and hysteretic behavior is difficult without specific measurements on complex systems such as the one shown in this manuscript. Further studies are needed to demonstrate the role of deformation bands on $\mathrm{CO}_{2}$ residual trapping.

Geometrically similar compartmentalization to that observed in Fig. 5 can be expected to occur at $\mathrm{m}$ and $\mathrm{km}$ scales, where individual compartments are bounded by multiple deformation band clusters or sub-seismic faults (as opposed to individual conjugate bands). Simulations similar to those in Figs. 6 and 7, but up-scaled to represent compartmentalization at reservoir scales, should be used to assess storage capacity at proposed sites. To develop realistic geological models for implementation in such reservoir models, robust estimations of the petrophysical properties of deformation bands, deformation band clusters and sub-seismic deformation-band dominated faults, as well as their likely geometric configurations and frequencies, are required. These can only be derived from outcrop analogues and detailed structural geological studies (fault and fractures logs, micro-structural analysis) (Fox and Bowman, 2010).

\section{Conclusion}

In this study, $\mathrm{N}_{2}$ /water drainage capillary pressure experiments were conducted in a sandstone core characterized by diversely oriented clusters of deformation bands. Clusters of deformation bands and single deformation bands subdivide the host rock into several compartments. Results show that $\mathrm{N}_{2}$ migrates through tortuous pathways and that limited connectivity exists between compartments. Compartments close to the inlet reach very high saturations from the outset of $\mathrm{N}_{2}$ injection into the fully water-saturated sample. The increase in $\mathrm{N}_{2}$ saturation is mostly due to the presence of a diagonally oriented thick cluster of bands 
a)

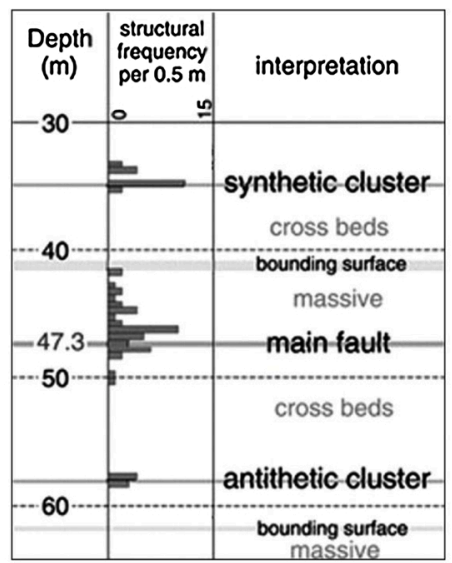

b)

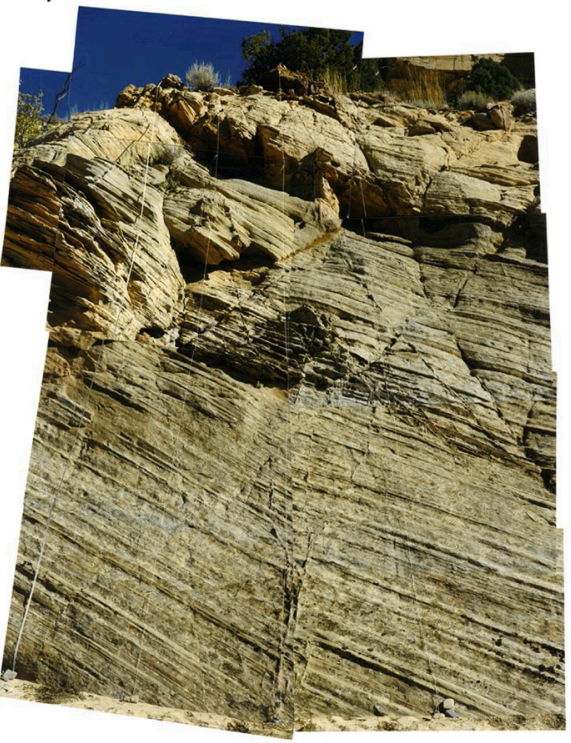

c)

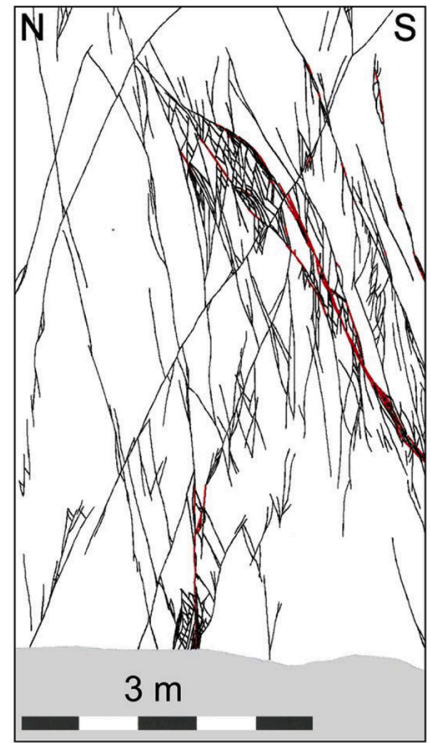

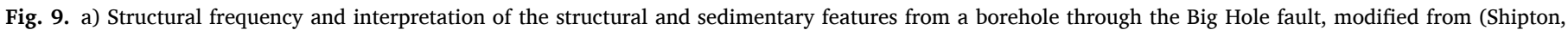

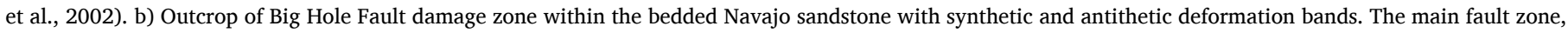

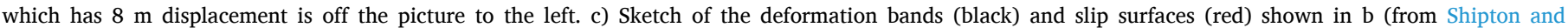
Cowie, 2001).

that traverses the sample and acts as a capillary barrier. The saturation of pores beyond this cluster happens only when $\mathrm{N}_{2}$ breaches through short sections of the bands. These sections may be linked to discontinuities or to lower capillary entry pressure regions within the bands. Subdivision of one host rock compartment is also caused by a thin single deformation band, oriented parallel to flow. At the end of the experiment, most of the deformation bands themselves and two large compartments towards the outlet of the rock sample remain unsaturated with $\mathrm{N}_{2}$, even with a high differential pressure (1.95 MPa) across the core. Small compartments enclosed by thick clusters of bands also show low $\mathrm{N}_{2}$ saturation. A detailed analysis of the temporal evolution of $\mathrm{N}_{2}$ saturation in individual compartments towards the outlet was conducted. At the end of the experiment, individual compartments retain very different $\mathrm{N}_{2}$ saturation values. Because of the complex tortuosity of the network, and the fact that $\mathrm{N}_{2}$ can travel out of the plane of observation, some compartments at a greater distance from inlet have higher saturations than those that are closer.

Each time the $\mathrm{N}_{2}$ inflow rate is increased to a new value, the differential pressure across the core rises to a peak. At the peak, additional compartment(s) are invaded and the differential pressure then drops to a new steady value. The peak values are remarkably consistent lying between 1.3 MPa and 1.95 MPa and likely represent the range of capillary entry pressure values for the deformation band clusters.

Numerical modeling of a simplified 2D representation of the core was conducted to understand the role of experimental conditions and of discontinuities in the bands. Simulations show that the low saturation in compartments close to the outlet is caused by the experimental conditions; commonly termed the capillary end effect. The introduction of discontinuities in some of the modeled bands increased the likelihood of individual compartments being entirely by-passed and remaining at zero saturation, as observed in the experiment.

This research highlights the potential for deformation bands to act as extreme capillary barriers and to result in reservoir fluid compartmentalization. A potential $\mathrm{CO}_{2}$ or oil reservoir may be characterized by synthetic and antithetic sub-seismic faults with associated synthetic and antithetic clusters of deformation bands. A detailed statistical characterization of petrophysical band properties and band geometries is required, at a reservoir scale, to improve probabilistic models of reservoir storage predictions.

\section{Data availability}

Micro-CT images, experimental results, and simulations are stored at https://doi.org/10.15129/13fb3063-44bc-422e-9c33-c22e62bc0d90.

\section{CRediT authorship contribution statement}

Carla R. Romano: Investigation, Data curation, Formal analysis, Visualization, Writing - original draft. Charlotte Garing: Investigation, Writing - review \& editing. James M. Minto: Investigation, Writing review \& editing, Supervision. Sally M. Benson: Conceptualization, Resources, Supervision, Writing - review \& editing, Funding acquisition. Zoe K. Shipton: Conceptualization, Resources, Supervision, Writing review \& editing, Funding acquisition. Rebecca J. Lunn: Conceptualization, Resources, Supervision, Writing - review \& editing, Funding acquisition.

\section{Declaration of Competing Interest}

The authors declare that they have no known competing financial interests or personal relationships that could have appeared to influence the work reported in this paper.

\section{Acknowledgments}

Authors would like to thank James P. Evans for providing the core sample and Christopher Zahasky for the support during the experiment. The experimental work was funded in part by the Global Climate and Energy Project. C.R.Romano was funded through aUniversity of Strathclyde PhD Scholarship and travel through the University of Strathclyde Global Engagement Fund. 


\section{Appendix A. Supplementary data}

Supplementary material related to this article can be found, in the online version, at doi:https://doi.org/10.1016/j.ijggc.2021.103280.

\section{References}

Ader, J.C., Stein, M.H., 1984. Slaughter estate unit tertiary miscible gas pilot reservoir description. J. Pet. Technol. 36 (05), 837-845.

Akbarabadi, M., Piri, M., 2013. Relative permeability hysteresis and capillary trapping characteristics of supercritical CO2/brine systems: an experimental study at reservoir conditions. Adv. Water Resour. 52, 190-206.

Akin, S., Kovscek, A.R., 2003. Computed tomography in petroleum engineering research Geol. Soc. Lond. Spec. Publ. 215 (1), 23-38.

Alemu, B.L., Aker, E., Soldal, M., Johnsen, Ø., Aagaard, P., 2013. Effect of sub-core scale heterogeneities on acoustic and electrical properties of a reservoir rock: a $\mathrm{CO} 2$ flooding experiment of brine saturated sandstone in a computed tomography scanner. Geophys. Prospect. 61 (1), 235-250.

Al-Menhali, A., Niu, B., Krevor, S., 2015. Capillarity and wetting of carbon dioxide and brine during drainage in B erea sandstone at reservoir conditions. Water Resour. Res. 51 (10), 7895-7914.

Antonellini, M., Aydin, A., 1994. Effect of faulting on fluid flow in porous sandstones: petrophysical properties. AAPG Bull. 78 (3), 355-377.

Antonellini, M., Aydin, A., 1995. Effect of faulting on fluid flow in porous sandstones: geometry and spatial distribution. AAPG Bull. 79 (5), 642-670.

Antonellini, M., Mollema, P., 2002. Cataclastic faults in the Loiano sandstones; northern Apennines, Italy. Bollettino della Società Geologica Italiana 121 (2), 163-178.

Antonellini, M., Aydin, A., Orr, L., 1999. Outcrop-aided characterization of a faulted hydrocarbon reservoir: Arroyo Grande oil field, California, USA. GMS 113, 7-26.

Aydin, A., 1978. Small faults formed as deformation bands in sandstone. Rock Friction and Earthquake Prediction, pp. 913-930.

Aydin, A., Johnson, A.M., 1978. Development of faults as zones of deformation bands and as slip surfaces in sandstone. Pure Appl. Geophys. 116 (4-5), 931-942.

Ballas, G., Fossen, H., Soliva, R., 2015. Factors controlling permeability of cataclastic deformation bands and faults in porous sandstone reservoirs. J. Struct. Geol. 76, $1-21$.

Berg, S.S., Skar, T., 2005. Controls on damage zone asymmetry of a normal fault zone: outcrop analyses of a segment of the Moab fault, SE Utah. J. Struct. Geol. 27 (10), 1803-1822.

Bonson, C.G., Childs, C., Walsh, J.J., Schöpfer, M.P., Carboni, V., 2007. Geometric and kinematic controls on the internal structure of a large normal fault in massive limestones: the Maghlaq Fault, Malta. J. Struct. Geol. 29 (2), 336-354.

Boon, M., Ni, H., Garing, C., Benson, S.M., 2018. Effect of capillary induced flow on CO2 residual trapping. Melbourne, 14th Greenhouse Gas Control Technologies Conference. GHGT 21-26.

Brooks, R.H., Corey, A.T., 1964. Hydraulic Properties of Porous Media. Hydrology Papers. Colorado State University, pp. 22-27.

Brown, H.W., 1951. Capillary pressure investigations. J. Pet. Technol. 3 (03), 67-74.

Caine, J.S., Evans, J.P., Forster, C.B., 1996. Fault zone architecture and permeability structure. Geology 24 (11), 1025-1028.

Cao, H., 2002. Development of Techniques for General Purpose Simulators. Stanford University. Doctoral dissertation.

Cao, H., Aziz, K., 2002. Performance of IMPSAT and IMPSAT-AIM models in compositional simulation. SPE Annual Technical Conference and Exhibition, Society of Petroleum Engineers.

Cardwell Jr., W.T., Parsons, R.L., 1945. Average permeabilities of heterogeneous oil sands. Trans. Aime 160 (01), 34-42.

Chadwick, R.A., Zweigel, P., Gregersen, U., Kirby, G.A., Holloway, S., Johannessen, P.N., 2004. Geological reservoir characterization of a CO2 storage site: the Utsira Sand, Sleipner, northern North Sea. Energy 29 (9-10), 1371-1381.

Chandler, M.A., Kocurek, G., Goggin, D.J., Lake, L.W., 1989. Effects of stratigraphic heterogeneity on permeability in eolian sandstone sequence, Page Sandstone, northern Arizona. AAPG Bull. 73 (5), 658-668.

Childs, C., Manzocchi, T., Walsh, J.J., Bonson, C.G., Nicol, A., Schöpfer, M.P., 2009. A geometric model of fault zone and fault rock thickness variations. J. Struct. Geol. 31 (2), 117-127.

Cnudde, V., Boone, M.N., 2013. High-resolution X-ray computed tomography in geosciences: a review of the current technology and applications. Earth. Rev. 123, $1-17$.

Cowton, L.R., Neufeld, J.A., White, N.J., Bickle, M.J., Williams, G.A., White, J.C., Chadwick, R.A., 2018. Benchmarking of vertically-integrated CO2 flow simulations at the Sleipner Field, North Sea. Earth Planet. Sci. Lett. 491, 121-133.

Del Sole, L., Antonellini, M., 2019. Microstructural, petrophysical, and mechanical properties of compactive shear bands associated to calcite cement concretions in arkose sandstone. J. Struct. Geol. 126, 51-68.

Del Sole, L., Antonellini, M., Soliva, R., Ballas, G., Balsamo, F., Viola, G., 2020. Structural control on fluid flow and shallow diagenesis: insights from calcite cementation along deformation bands in porous sandstones. Solid Earth Discuss. 1-48.

Deng, S., Zuo, L., Aydin, A., Dvorkin, J., Mukerji, T., 2015. Permeability characterization of natural compaction bands using core flooding experiments and three-dimensiona image-based analysis: comparing and contrasting the results from two different methods. AAPG Bull. 99 (1), 27-49.

Edlmann, K., Bensabat, J., Niemi, A., Haszeldine, R.S., McDermott, C.I., 2016. Lessons learned from using expert elicitation to identify, assess and rank the potential leakage scenarios at the Heletz pilot CO2 injection site. Int. J. Greenh. Gas Control. 49, 473-487.

Eiken, O., Ringrose, P., Hermanrud, C., Nazarian, B., Torp, T.A., Høier, L., 2011. Lessons learned from 14 years of CCS operations: Sleipner, In Salah and Snøhvit. Energy Procedia 4, 5541-5548.

Fisher, Q., Phillips, G., Li, A., Condliffe, D., 2005. Petrophysical Properties of Fault Rocks Slochteren Sandstone, Offshore and Onshore Netherlands. Prop. report for Total: Rock Deformation Research Ltd., Leeds.

Fossen, H., Hesthammer, J., 1997. Geometric analysis and scaling relations of deformation bands in porous sandstone. J. Struct. Geol. 19 (12), 1479-1493.

Fossen, H., Schultz, R.A., Shipton, Z.K., Mair, K., 2007. Deformation bands in sandstone: a review. J. Geol. Soc. 164 (4), 755-769.

Fossen, H., Soliva, R., Ballas, G., Trzaskos, B., Cavalcante, C., Schultz, R.A., 2018. A review of deformation bands in reservoir sandstones: geometries, mechanisms and distribution. Geol. Soc. Lond. Spec. Publ. 459 (1), 9-33.

Fox, R.J., Bowman, M.B.J., 2010. The challenges and impact of compartmentalization in reservoir appraisal and development. Geol. Soc. Lond. Spec. Publ. 347 (1), 9-23.

Gainski, M., Macgregor, A.G., Freeman, P.J., Nieuwland, H.F., 2010. Turbidite reservoir compartmentalization and well targeting with 4D seismic and production data: Schiehallion Field, UK. Geol. Soc. Lond. Spec. Publ. 347 (1), 89-102.

Garing, C., Benson, S.M., 2019. CO2 wettability of sandstones: addressing conflicting capillary behaviors. Geophys. Res. Lett. 46 (2), 776-782.

Gershenzon, N.I., Soltanian, M., Ritzi Jr., R.W., Dominic, D.F., 2014. Influence of small scale heterogeneity on $\mathrm{CO} 2$ trapping processes in deep saline aquifers. Energy Procedia 59, 166-173.

Gill, C.E., Shepherd, M., Millington, J.J., 2010. Compartmentalization of the Nelson field, Central North Sea: evidence from produced water chemistry analysis. Geol. Soc. Lond. Spec. Publ. 347 (1), 71-87.

Griffiths, J., Faulkner, D.R., Edwards, A.P., 2018. Deformation band development as a function of intrinsic host-rock properties in Triassic Sherwood Sandstone. Geol. Soc. Lond. Spec. Publ. 435 (1), 161-176.

Hansen, O., Gilding, D., Nazarian, B., Osdal, B., Ringrose, P., Kristoffersen, J.B., Eiken, O., Hansen, H., 2013. Snøhvit: the history of injecting and storing 1 Mt CO2 in the fluvial Tubåen Fm. Energy Procedia 37, 3565-3573.

Hingerl, F.F., Yang, F., Pini, R., Xiao, X., Toney, M.F., Liu, Y., Benson, S.M., 2016 Characterization of heterogeneity in the Heletz sandstone from core to pore scale and quantification of its impact on multi-phase flow. Int. J. Greenh. Gas Control. 48, 69-83.

Jackson, S.J., Krevor, S., 2019. Characterization of hysteretic multiphase flow from the $\mathrm{mm}$ to $\mathrm{m}$ scale in heterogeneous rocks. E3S Web of Conferences.EDP Sciences. 89, 02001.

Jenning, J.B., 1987. Capillary pressure techniques: application to exploration and development geology. AAPG Bull. 71 (10), 1196-1209.

Jiang, Y., 2008. Techniques for Modeling Complex Reservoirs and Advanced Wells. Stanford University. Doctoral dissertation.

Johansen, T.E.S., Fossen, H., 2008. Internal geometry of fault damage zones in interbedded siliciclastic sediments. Geol. Soc. Lond. Spec. Publ. 299 (1), 35-56.

Jolley, S.J., Fisher, Q.J., Ainsworth, R.B., 2010. Reservoir compartmentalization: an introduction. Geol. Soc. Lond. Spec. Publ. 347 (1), 1-8.

Kim, Y.S., Peacock, D.C., Sanderson, D.J., 2004. Fault damage zones. J. Struct. Geol. 26 (3), 503-517.

Krause, M.H., 2012. Modeling and investigation of the influence of capillary heterogeneity on relative permeability. SPE Annual Technical Conference and Exhibition, Society of Petroleum Engineers.

Krause, M., Krevor, S., Benson, S.M., 2013. A procedure for the accurate determination of sub-core scale permeability distributions with error quantification. Transp. Porous Media 98 (3), 565-588.

Krevor, S.C., Pini, R., Li, B., Benson, S.M., 2011. Capillary heterogeneity trapping of CO2 in a sandstone rock at reservoir conditions. Geophys. Res. Lett. 38 (15).

Krevor, S.C., Pini, R., Zuo, L., Benson, S.M., 2012. Relative permeability and trapping of $\mathrm{CO} 2$ and water in sandstone rocks at reservoir conditions. Water Resour. Res. 48 (2).

Krevor, S., Blunt, M.J., Benson, S.M., Pentland, C.H., Reynolds, C., Al-Menhali, A., Niu, B., 2015. Capillary trapping for geologic carbon dioxide storage-From pore scale physics to field scale implications. Int. J. Greenh. Gas Control. 40, 221-237.

Leveille, G.P., Knipe, R., More, C., Ellis, D., Dudley, G., Jones, G., Fisher, Q.J., Allinson, G., 1997. Compartmentalization of Rotliegendes gas reservoirs by sealing faults, Jupiter Fields area, southern North Sea. Geol. Soc. Lond. Spec. Publ. 123 (1), 87-104.

Lewis, H., Couples, G.D., 1993. Production evidence for geological heterogeneities in the Anschutz Ranch East field, western USA. Geol. Soc. Lond. Spec. Publ. 73 (1), 321-338.

Li, B., 2011. Including Fine-scale Capillary Heterogeneity in Modeling the Flow of CO2 and Brine in Reservoir Cores. Doctoral dissertation. Stanford University.

Li, B., Benson, S.M., 2015. Influence of small-scale heterogeneity on upward CO2 plume migration in storage aquifers. Adv. Water Resour. 83, 389-404.

Li, B., Benson, S.M., Tchelepi, H.A., 2012. Modeling fine-scale capillary heterogeneity in multiphase flow of $\mathrm{CO} 2$ and brine in sedimentary rocks. University of Illinois at Urbana-Champaign, IL, USA, Proceedings of the XIX International Conference on Water Resources.

Li, Y., Li, H., Chen, S., Luo, H., Liu, C., 2020. Investigation of the dynamic capillary pressure during displacement process in fractured tight rocks. Aiche J. 66 (1).

Lunn, R.J., Shipton, Z.K., Bright, A.M., 2008. How can we improve estimates of bulk fault zone hydraulic properties? Geol. Soc. Lond. Spec. Publ. 299 (1), 231-237.

Malik, Q.M., Islam, M.R., 2000. CO2 injection in the weyburn field of Canada: optimization of enhanced oil recovery and greenhouse gas storage with horizonta 
wells. In: SPE/DOE ImprovedOilRecoverySymposium. Society of Petroleum Engineers.

Meckel, T.A., Bryant, S.L., Ganesh, P.R., 2015. Characterization and prediction of CO2 saturation resulting from modeling buoyant fluid migration in 2D heterogeneous geologic fabrics. Int. J. Greenh. Gas Control. 34, 85-96.

Medeiros, W.E., Do Nascimento, A.F., da Silva, F.A., Destro, N., Demétrio, J.G.A., 2010. Evidence of hydraulic connectivity across deformation bands from field pumping tests: two examples from Tucano Basin, NE Brazil. J. Struct. Geol. 32 (11), $1783-1791$.

Medina, C.R., Rupp, J.A., Barnes, D.A., 2011. Effects of reduction in porosity and permeability with depth on storage capacity and injectivity in deep saline aquifers: a case study from the Mount Simon Sandstone aquifer. Int. J. Greenh. Gas Control. 5 (1), 146-156.

Mees, F., Swennen, R., Van Geet, M., Jacobs, P., 2003. Applications of X-ray computed tomography in the geosciences. Geol. Soc. Lond. Spec. Publ. 215 (1), 1-6.

Mezzomo, R.F., Luvizotto, J.M., Palagi, C.L., 2001. Improved oil recovery in Carmópolis field: R\&D and field implementations. Spe Reserv. Eval. Eng. 4 (01), 4-10.

Milkov, A.V., Goebel, E., Dzou, L., Fisher, D.A., Kutch, A., McCaslin, N., Bergman, D.F., 2007. Compartmentalization and time-lapse geochemical reservoir surveillance of the Horn Mountain oil field, deep-water Gulf of Mexico. AAPG Bull. 91 (6), 847-876.

Minto, J.M., Hingerl, F.F., Benson, S.M., Lunn, R.J., 2017. X-ray CT and multiphase flow characterization of a 'bio-grouted'sandstone core: the effect of dissolution on seal longevity. Int. J. Greenh. Gas Control. 64, 152-162.

Morad, S., Al-Ramadan, K., Ketzer, J.M., De Ros, L.F., 2010. The impact of diagenesis on the heterogeneity of sandstone reservoirs: a review of the role of depositional facies and sequence stratigraphy. AAPG Bull. 94 (8), 1267-1309.

Naruk, S.J., Wilkins, S., Davies, R., Bikun, J., Uzoh, O., Jensen, L., 2009. Subsurface observations of deformation bands and their impact on hydrocarbon production within the Holstein Field. S.L., 2nd EAGE International Conference on Fault and Top Seals - From Pore to Basin Scale 2009.

Ni, H., Boon, M., Garing, C., Benson, S.M., 2019. Predicting CO2 residual trapping ability based on experimental petrophysical properties for different sandstone types. Int. J. Greenh. Gas Control. 86, 158-176.

Niu, B., Al-Menhali, A., Krevor, S.C., 2015. The impact of reservoir conditions on the residual trapping of carbon dioxide in Berea sandstone. Water Resour. Res. 51 (4), 2009-2029.

Odling, N.E., Gillespie, P., Bourgine, B., Castaing, C., Chiles, J.P., Christensen, N.P., Fillion, E., Genter, A., Olsen, C., Thrane, L., Trice, R., 1999. Variations in fracture system geometry and their implications for fluid flow in fractures hydrocarbon reservoirs. Pet. Geosci. 5 (4), 373-384.

Perrin, J.C., Benson, S., 2010. An experimental study on the influence of sub-core scale heterogeneities on CO2 distribution in reservoir rocks. Transp. Porous Media 82 (1), 93-109.

Perrin, J.C., Krause, M., Kuo, C.W., Miljkovic, L., Charoba, E., Benson, S.M., 2009. Corescale experimental study of relative permeability properties of $\mathrm{CO} 2$ and brine in reservoir rocks. Energy Procedia 1 (1), 3515-3522.

Pini, R., Benson, S.M., 2013. Simultaneous determination of capillary pressure and relative permeability curves from core-flooding experiments with various fluid pairs. Water Resour. Res. 49 (6), 3516-3530.

Pini, R., Krevor, S.C., Benson, S.M., 2012. Capillary pressure and heterogeneity for the CO2/water system in sandstone rocks at reservoir conditions. Adv. Water Resour. 38, 48-59.

Plug, W.J., Bruining, J., 2007. Capillary pressure for the sand-CO2-water system under various pressure conditions. Application to $\mathrm{CO} 2$ sequestration. Adv. Water Resour. 30 (11), 2339-2353.

Pontes, C.C., Pontes, C.C., Nogueira, F.C., Bezerra, F.H., Balsamo, F., Miranda, T.S., Nicchio, M.A., Souza, J.A., Carvalho, B.R., 2019. Petrophysical properties of deformation bands in high porous sandstones across fault zones in the Rio do Peixe Basin, Brazil. Int. J. Rock Mech. Min. Sci. 114 (1), 153-163.

Qu, D., Tveranger, J., Fachri, M., 2017. Influence of deformation-band fault damage zone on reservoir performance. Interpretation 5 (4), SP41-SP56.

Rawling, G.C., Goodwin, L.B., Wilson, J.L., 2001. Internal architecture, permeability structure, and hydrologic significance of contrasting fault-zone types. Geology 29 (1), 43-46.

Richards, F.W., Vrolijk, P.J., Gordon, J.D., Miller, B.R., 2010. Reservoir connectivity analysis of a complex combination trap: Terra Nova Field, Jeanne d'Arc Basin, Newfoundland, Canada. Geol. Soc. Lond. Spec. Publ. 347 (1), 333-355.

Romano, C.R., Zahasky, C., Garing, C., Minto, J.M., Benson, S.M., Shipton, Z.K., Lunn, R. J., 2020. Sub-core scale fluid flow behavior in a sandstone with cataclastic deformation bands. Water Resour. Res. 56 (4).

Rotevatn, A., Fossen, H., 2011. Simulating the effect of subseismic fault tails and process zones in a siliciclastic reservoir analogue: implications for aquifer support and trap definition. Mar. Pet. Geol. 28 (9), 1648-1662.
Rotevatn, A., Fossmark, H.S., Bastesen, E., Thorsheim, E., Torabi, A., 2017. Do deformation bands matter for flow? Insights from permeability measurements and flow simulations in porous carbonate rocks. Pet. Geosci. 23 (1), 104-119.

Saadatpoor, E., Bryant, S.L., Sepehrnoori, K., 2010. New trapping mechanism in carbon sequestration. Transp. Porous Media 82 (1), 3-17.

Saillet, E., Wibberley, C.A., 2010. Evolution of cataclastic faulting in high-porosity sandstone, Bassin du Sud-Est, Provence, France. J. Struct. Geol. 32 (11), 1590-1608.

Schueller, S., Braathen, A., Fossen, H., Tverang, J., 2013. Spatial distribution of deformation bands in damage zones of extensional faults in porous sandstones: statistical analysis of field data. J. Struct. Geol. 52, 148-162.

Schultz, R.A., Balasko, C.M., 2003. Growth of deformation bands into echelon and ladder geometries. Geophys. Res. Lett. 30 (20).

Schultz, R.A., Siddharthan, R., 2005. A general framework for the occurrence and faulting of deformation bands in porous granular rocks. Tectonophysics 411 (1-4), $1-18$.

Scott, E.D., Gelin, F., Jolley, S.J., Leenaarts, E., Sadler, S.P., Elsinger, R.J., 2010. Sedimentological control of fluid flow in deep marine turbidite reservoirs: Pierce Field, UK Central North Sea. Geol. Soc. Lond. Spec. Publ. 347 (1), 113-132.

Sheng, J., 2013. Enhanced Oil Recovery Field Case Studies. Gulf Professional Publishing.

Shi, J.Q., Xue, Z., Durucan, S., 2011. Supercritical CO2 core flooding and imbibition in Tako sandstone-influence of sub-core scale heterogeneity. Int. J. Greenh. Gas Control. 5 (1), 75-87.

Shipton, Z.K., Cowie, P.A., 2001. Damage zone and slip-surface evolution over $\mu \mathrm{m}$ to $\mathrm{km}$ scales in high-porosity Navajo sandstone, Utah. J. Struct. Geol. 23 (12), 1825-1844.

Shipton, Z.K., Cowie, P.A., 2003. A conceptual model for the origin of fault damage zone structures in high-porosity sandstone. J. Struct. Geol. 25, 333-345.

Shipton, Z.K., Evans, J.P., Robeson, K.R., Forster, C.B., Snelgrove, S., 2002. Structural heterogeneity and permeability in faulted eolian sandstone: implications for subsurface modeling of faults. AAPG Bull. 86 (5), 863-883.

Shipton, Z.K., Evans, J.P., Thompson, L.B., 2005. The geometry and thickness of deformation-band fault core and its influence on sealing characteristics of deformation-band fault zones. Am. Assoc. Petrol. Geol. Memoir 85, 181-195.

Smith, D.A., 1980. Sealing and nonsealing faults in Louisiana Gulf Coast salt basin. AAPG Bull. 64 (2), 145-172.

Smith, P., 2008. Studies of United Kingdom Continental Shelf fields after a decade of production: how does production data affect the estimation of subsurface uncertainty? AAPG Bull. 92 (10), 1403-1413.

Sosio de Rosa, S., Shipton, Z.K., Lunn, R.J., Kremer, Y., Murray, T., 2018. Along-strike fault core thickness variations of a fault in poorly lithified sediments, Miri (Malaysia). J. Struct. Geol. 116, 189-206.

Taylor, W.L., Polland, D.D., 2000. Estimation of in situ permeability of deformation bands in porous sandstone, Valley of Fire, Nevada. Water Resour. Res. 36 (9), 2595-2606.

Tindall, S.E., 2006. Jointed deformation bands may not compartmentalize reservoirs. AAPG Bull. 90 (2), 177-192.

Torabi, A., 2014. Cataclastic bands in immature and poorly lithified sandstone, examples from Corsica, France. Tectonophysics 630, 91-102.

Torabi, A., Fossen, H., Braathen, A., 2013. Insight into petrophysical properties of deformed sandstone reservoirs. AAPG Bull. 97 (4), 619-637, 9.

Van Hulten, F.F., 2010. Geological factors effecting compartmentalization of Rotliegend gas fields in the Netherlands. Geol. Soc. Lond. Spec. Publ. 347 (1), 301-315.

van Ojik, K., Silvius, A., Kremer, Y., Shipton, Z.K., 2020. Fault seal behaviour in Permian Rotliegend reservoir sequences: case studies from the Dutch Southern North Sea. In: Ogilvie, S.R., Dee, S.J., Wilson, R.W., Bailey, W.R. (Eds.), Integrated Fault Seal Analysis. Geological Society, London, 496. Special Publications, pp. 9-38. NP, 7 July 2020.

Wang, G., Chang, X., Yin, W., Li, Y., Song, T., 2017. Impact of diagenesis on reservoir quality and heterogeneity of the Upper Triassic Chang 8 tight oil sandstones in the Zhenjing area, Ordos Basin, China. Mar. Pet. Geol. 83, 84-96.

Wilkins, S.J., Davies, R.K., Naruk, S.J., 2019. Subsurface Observations of Deformation Bands and Their Impact on Hydrocarbon Production Within the Holstein Field, 496. Geological Society, London, Volume Special Publications, Gulf of Mexico, USA pp. SP496-2018.

Williams, R.T., Goodwin, L.B., Mozley, P.S., 2017. Diagenetic controls on the evolution of fault-zone architecture and permeability structure: implications for episodicity of fault-zone fluid transport in extensional basins. GSA Bulletin 129 (3-4), 464-478.

Willis, B.J., White, C.D., 2000. Quantitative outcrop data for flow simulation. J. Sediment. Res. 70 (4), 788-802.

Withjack, E.M., 1988. Computed tomography for rock-property determination and fluidflow visualization. Spe Form. Eval. 3 (04), 696-704. 